\title{
Biomarkers in Pancreatic Cancer as Analytic Targets for Nanomediated Imaging and Therapy
}

\author{
Cristiana Maria Grapa ${ }^{1,2}$, Lucian Mocan ${ }^{2,3, *}$, Dana Crisan ${ }^{4}$, Mira Florea ${ }^{5}{ }^{\complement}$ and Teodora Mocan ${ }^{1,2}$ \\ 1 Physiology Department, “Iuliu Hatieganu” University of Medicine and Pharmacy, 400126 Cluj-Napoca, \\ Romania; grapa.cristiana.maria@umfcluj.ro (C.M.G.); teodora.mocan@umfcluj.ro (T.M.) \\ 2 Nanomedicine Department, Regional Institute of Gastroenterology and Hepatology, \\ 400126 Cluj-Napoca, Romania \\ 3 3-rd Surgery Clinic, University of Medicine and Pharmacy, 400126 Cluj-Napoca, Romania \\ 4 Internal Medicine Department, “Iuliu Hatieganu” University of Medicine and Pharmacy, 400126 Cluj-Napoca, \\ Romania; crisan.dc@gmail.com \\ 5 Family Medicine Department, Iuliu Hatieganu University of Medicine and Pharmacy, 400126 Cluj-Napoca, \\ Romania; miraflorea@umfcluj.ro \\ * Correspondence: lucian.mocan@umfcluj.ro
}

Citation: Grapa, C.M.; Mocan, L.; Crisan, D.; Florea, M.; Mocan, T.

Biomarkers in Pancreatic Cancer as Analytic Targets for Nanomediated Imaging and Therapy. Materials 2021, 14, 3083. https://doi.org/10.3390/ ma14113083

Academic Editor: Arunas

Ramanavicius

Received: 19 May 2021

Accepted: 2 June 2021

Published: 4 June 2021

Publisher's Note: MDPI stays neutral with regard to jurisdictional claims in published maps and institutional affiliations.

Copyright: (c) 2021 by the authors. Licensee MDPI, Basel, Switzerland. This article is an open access article distributed under the terms and conditions of the Creative Commons Attribution (CC BY) license (https:// creativecommons.org/licenses/by/ $4.0 /)$.
Abstract: As the increase in therapeutic and imaging technologies is swiftly improving survival chances for cancer patients, pancreatic cancer (PC) still has a grim prognosis and a rising incidence. Practically everything distinguishing for this type of malignancy makes it challenging to treat: no approved method for early detection, extended asymptomatic state, limited treatment options, poor chemotherapy response and dense tumor stroma that impedes drug delivery. We provide a narrative review of our main findings in the field of nanoparticle directed treatment for PC, with a focus on biomarker targeted delivery. By reducing drug toxicity, increasing their tumor accumulation, ability to modulate tumor microenvironment and even improve imaging contrast, it seems that nanotechnology may one day give hope for better outcome in pancreatic cancer. Further conjugating nanoparticles with biomarkers that are overexpressed amplifies the benefits mentioned, with potential increase in survival and treatment response.

Keywords: biomarkers; nanoparticles; pancreatic cancer; targeted therapy

\section{Introduction}

All studies involving pancreatic cancer start with the same harrowing observation: this type of cancer has one of the worst outcomes, with high morbidity and mortality, its survival rate being lower than $10 \%$ [1]. It is expected that by the year 2030, PC will be the second cause of cancer-related deaths [2]. Regarding its histology, 90\% of all tumors are pancreatic adenocarcinomas (PDAC), which arise from the ductal epithelium of the exocrine pancreas. Its long asymptomatic state and its rapid growth, along with poor treatment response are responsible for a median survival of 5 to 8 months, following diagnosis [3].

The only curative treatment is represented by surgery, but only about $20 \%$ benefit from it, as PC is often asymptomatic and most of them are diagnosed in late stages; furthermore, even for patients who undergo surgical treatment, up to $80 \%$ still progress to local recurrence or metastases [4]. Chemotherapy regimens available are represented by gemcitabine as first line treatment; FOLFIRINOX (a combination of four chemotherapeutics: follinic acid,5-fluorouracil, oxaliplatin and irinotecan) and recently, albumin bound paclitaxel [5]. Liposomal irinotecan was also approved as of late for patients with advanced disease, but due to its important toxicity, its use in current clinical practice is being questioned [6].

Intrinsic barriers such as drug resistance and extrinsic cell barriers, mainly represented by the tumor microenvironment, need to be overcome in order to properly manage this type of cancer. Current treatment modalities are insufficient, thus, effort was put into 
developing new and improved therapeutic strategies. Nanotechnology plays an important part in the development of tumor targeted therapies; nanoparticles, through their small size, ability to breach tumor barriers and gather into the neoplastic tissue hold great promise for overcoming obstacles in pancreatic cancer treatment [7]. Moving forward, nanoparticle targeted therapy can further increase their prospective use.

Aside from carbohydrate antigen CA 19-9, a biomarker which is not completely specific to pancreatic cancer, no other biomarker has been approved for diagnosis, prognosis or early detection in PC. Early screening for PC using imaging techniques, like computer tomography (CT) or magnetic resonance (MRI) are not recommended, mainly due to cost-efficiency and their inability to detect pancreatic lesions smaller than 5-8 $\mathrm{mm}$ [8].

Recent studies have demonstrated the potential use of a multitude of biomarkers for early detection, prognosis or treatment follow-up, although larger validation studies are required. Nanoparticle targeted therapies using biomarkers is a rapidly evolving field of research. Multiple types of nanoparticles such as magnetic iron oxide nanoparticles, single wall carbon nanotubes and others $[9,10]$ have been used on different pancreatic cancer cell lines along with biomarkers which proved to be beneficial in augmenting the nanoconjugates therapeutic efficacy. The biomarkers used appeared to enhance either accumulation of the nanoparticles used, the chemotherapy effectiveness or contrast imaging, proving that despite the fact that there is still a long way to go until clinical implementation, steps are made in the right direction. The main purpose of our research is to emphasize the potential impact of nanotechnology in pancreatic cancer, a type of cancer with very limited therapy options.

In this narrative review, we provide an outline of the main therapeutic obstacles in pancreatic cancer, and the potential use of nanotechnology and biomarker targeted therapy for diminishing the burden of this disease. We searched the Medline/PubMed database for eligible articles using specific keywords like "pancreatic cancer", "stroma", "biomarker", "nanoparticle", "nanotechnology" and "targeted therapy" together or in combinations. We selected the articles based on their relevance for our desired approach and included the ones that met our criteria: nanotechnology and its involvement in pancreatic cancer therapy. Only English written articles were included; almost all articles were published from January 2001 to February 2021, with few exceptions we could not exclude because of their significance.

\section{Results and Discussions}

\subsection{Pancreatic Tumor Microenvironment and Therapeutic Challenges}

An abundant number of new diagnostic and therapeutic prospects emerged in the past years involving different types of cancer; regrettably, PDAC prognosis remains grim. The main reason is thought to be the pancreatic tumor microenvironment (TME), or pancreatic stroma [11]. The TME is composed of both cancer cells and other types of cells that make up the stroma (Figure 1), including stellate pancreatic cells (PSC), cancer-associated fibroblasts, immune and endothelial cells [12]. Additionally, TME encompasses the extracellular matrix proteins (ECM), along with other proteins produced by its cells. The interaction between cancer and stromal cells has been considered an important factor in cancer progression. Abundant stroma is considered to be a distinctive marker of pancreatic cancer, which contributes to the production of growth factors, extracellular matrix protein secretion and fibroblast activation [13]. A study comparing pancreatic cancer cell lines growing in different tumor microenvironments, using orthotopic tumor models, suggested that there are two processes that occur in the TME that can determine the features and conduct of cancer cells, namely, selection and education. In the selection process, some cancer cells become dominant, because of highly malignant characteristics; in the education part, cells attain a malignant phenotype through interaction with TME [14].

One of the main contributors to stromal variation is embodied by PSC. They are thought to participate in stromal activation and PC development. They exist in the normal pancreatic tissue as vitamin A and fat droplets carriers, but in PDAC, once activated, have 
the ability to induce aberrant secretion of matrix proteins, such as fibronectin, proteoglycans, laminin and glycoproteins in the ECM [15]. Their myofibroblast-like features lead to fibrosis and deviant desmoplasia [16]. The extreme production of ECM thus leads to a desmoplastic environment, which is responsible for drug resistance [17], aberrant vascular perfusion and decreased nutrient accessibility [18]. Another contributor to tumor progression is represented by cancer-associated fibroblasts (CAFs), which play an important role in tumorstromal interaction [19]. Interestingly, PSCs are thought to be precursors of CAFs [20], and while CAFs can display both pro and anti-tumorigenic proprieties, they are usually correlated with worse outcomes in PDAC patients [21]. CAFs have been linked to extensive tumor development and metastasis in PC [22]. Due to the continuous cell production which contributes to the impenetrable stroma and the lymphatic collapse which occurs in the center of the tumor, up to $80 \%$ of the blood vessels in PC are non-functional, bordered by a dense layer of pericityes, thus further impeding drug accumulation [23].

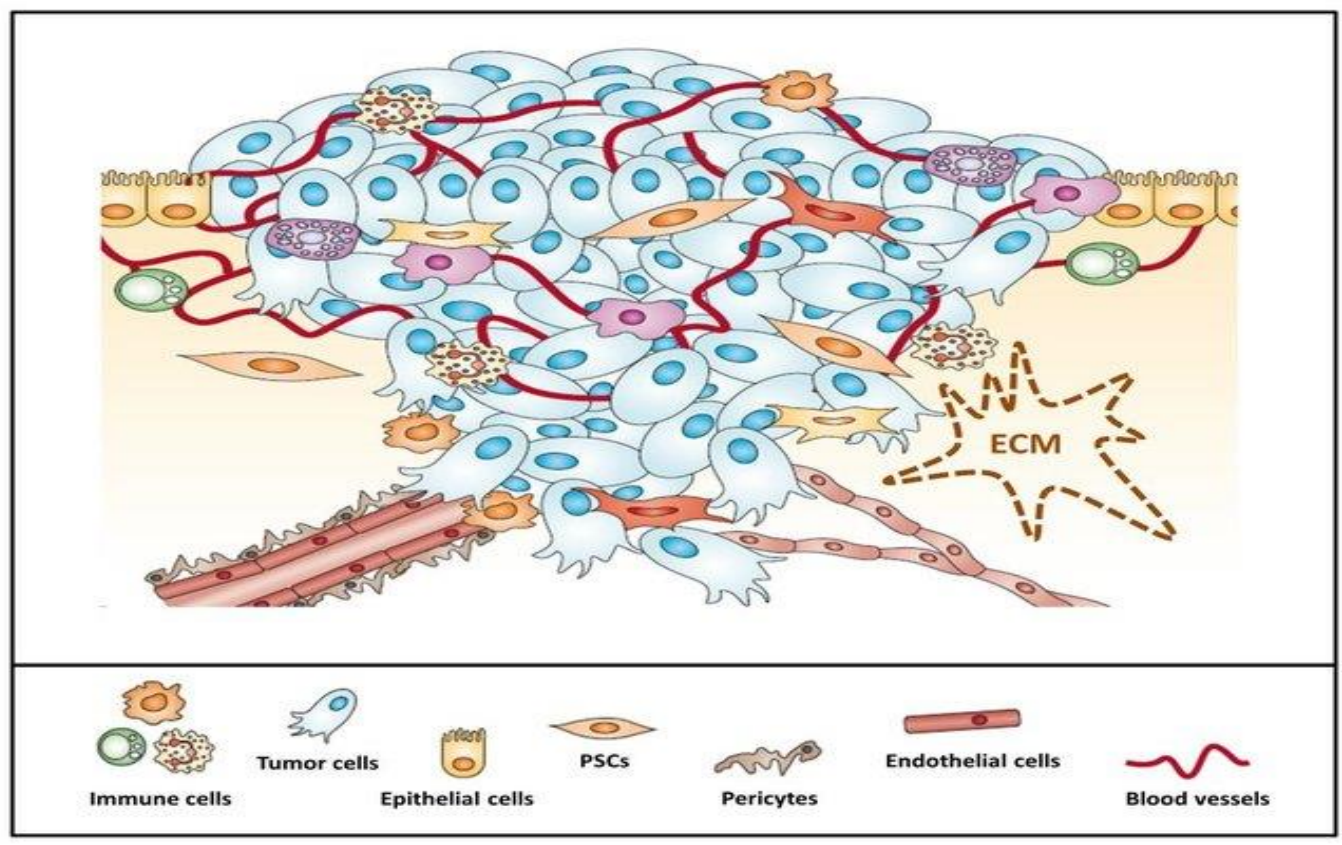

Figure 1. Pancreatic tumor microenvironment is composed of neoplastic cells surrounded by the abundant stroma at the cells that contribute to its development: pancreatic stellate cells (PSCs), immune cells such as neutrophils or lymphocytes, epithelial and endothelial cells and pericytes. Reprinted with permission from [24].

The main pathways involved in development and maintaining the abundant desmoplasia appear to be the vascular endothelial growth factor (VEGF) pathway, which then activates the Ras/Raf/Mek and phosphoinositide 3 kinase (PI3K)/Akt/mTOR pathways; their initiation promotes tumor proliferation, survival and metastasis [25]. A meta-analysis of clinical trials involving stromal targeting agents in pancreatic cancer metastasis [25] found that most trials (51) were directed to angiogenesis, with half of them $(26 / 51)$ including bevacizumab (anti-VEGF agent), although, unfortunately, several phase II and III trials showed no benefit for its use. Another important pathway in PC is the Hedgehog (Hh) pathway; it appears that it's ligand, Sonic Hedgehog (Shh) is highly expressed in over 70\% of PC cell lines. Olive et al. used mouse models to prove that administering saridegib, an Shh inhibitor, can lead to augmented gemcitabine delivery [26]. However, saridegib is still only used in clinical trials. These results prove that there are still challenges in developing a TME targeted therapy. 


\subsection{Nanotechnology and Targeted Therapy}

Nanomedicine involves the use of inorganic nanoparticles, such as gold, silica, iron oxide nanoparticles and organic ones, including micelles, polymeric or lipid nanostructures (Figure 2). Nanoparticles have many qualities like a small size (they represent the billionth portion of a meter), low toxicity, they have the ability to be used for targeted therapy and their surface can be adapted for better cell interaction, making them of great value for improving diagnosis and therapy in cancer [27]. As nano-sized transport vehicles, they have overcome many barriers and are of utmost importance in the era of precision medicine. They have been demonstrated to passively mount up in different types of tumors due to the enhanced permeability and retention (EPR) effect [28], or they can actively interact with tumor cells using ligands [29].

In pancreatic cancer, the EPR effect is insufficient, due to dense stroma; therefore, remodeling the TME is necessary to improve drug delivery and nanoparticle distribution. Generally, TME characteristics favor nanoparticle accumulation, but restrict their distribution and extravasation; so far, researchers have tried to overcome these obstacles by influencing tumor vasculature, tumor stress levels or degradation of extracellular matrix $[30,31]$.

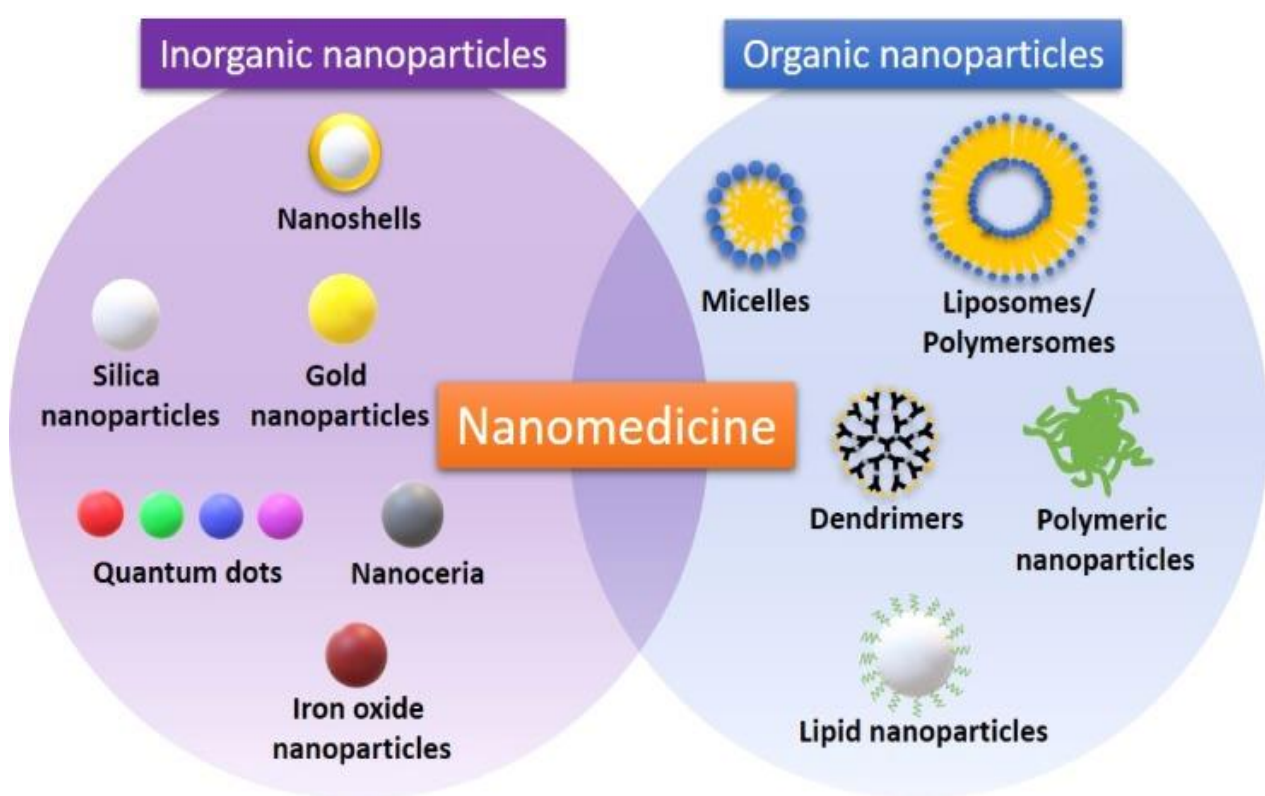

Figure 2. Examples of organic and inorganic nanoparticles used in the field of nanomedicine. Reprinted with permission from [32].

Clinical trials involving different types of nanoparticles, such as nanoparticle albumin bound paclitaxel (nab-paclitaxel), gold and micelle nanoparticles, or nanoparticles containing a retroviral gene for targeted therapy in PC have shown promising results so far [33]. Nab-paclitaxel in combination with Gemcitabine has even been approved in 2013 as a first line treatment in metastatic PC, for patients who are not eligible for other, more aggressive therapeutic options; it modestly improves survival by 1.8 months compared to gemcitabine alone [34]. Liposomal irinotecan was also approved in 2016 for patients with metastatic PC, although this treatment also comes with high toxicity [6]. Rexin-G, a gene therapy vector, was used in combination with nanoparticles, in several Phase I/II trials, for treatment of metastatic pancreatic cancer. The grouping showed good results, with improved survival and no organ toxicity [35-37]. Micelle nanoparticles encapsulating paclitaxel were used in metastatic PC in a phase I trial, showing an improved anti-tumor activity due to the EPR effect [38]. A nanoparticle composed of liposomes and cisplatin (lipoplatin) in combination with gemcitabine was used for patients with refractory PC, showing a median survival rate of four moths [39]. Generally, these trials have demonstrated that nanoparticles used in 
combination with chemotherapy is a safe therapeutic option, with low toxicity and great improvement of tumor targeting.

Researchers have also implemented the use of nanoparticles for tumor microenvironment remodeling. Han et al. [40]. established a system based on PEGylated polyethylenimine gold nanoparticles, together with all-trans retinoic acid, which has the ability to lead to PSC quiescence and siRNA targeting heat shock protein 47 , which leads to CAFs quiescence, obtaining an increase in the efficacy of gemcitabine treatment by TME modeling. Cun et al. [41]. Developed a combination of size-switchable dendrigraft poly-l-lysine nanoparticles with Gemcitabine (DLG/GEM) and 18 $\beta$-glycyrrhetinic acid loaded poly(ethyelene glycol)-poly(caprolactone)(PP/GA) for down-regulating CAFs. In addition to remodeling TME, the group also succeeded to enhance the tumor penetration of GEM, with a superior anti-tumor activity, compared to controls. In another attempt to improve drug delivery by surpassing the abundant stroma of PDAC, a team of researchers used collagenase loaded liposomes as a pre-treatment, following then a treatment with paclitaxel loaded micelles; the strategy managed to degrade the ECM and escalate therapeutic effect on a mouse model of PDAC [42].

The use of nanotechnology represents a distinctive prospect for directed distribution of chemotherapy into the tumor cells, improved imaging contrast, these strategies also leading to decreased side effects compared to systemic chemotherapy. These advantages have clear benefit on patient's quality of life and potentially their survival. Still, there is a clear need for better identification of subjects who might best benefit these therapeutic options, in order to properly develop individualized treatment schemes.

\subsection{Biomarkers in Pancreatic Cancer}

When talking about the early detection of pancreatic cancer, no current study When talking about the early detection of pancreatic cancer, no current study endorses screening asymptomatic patients. Nevertheless, there are certain high-risk categories (patients with hereditary history of pancreatic cancer, hereditary pancreatitis, Peutz-Jeghers syndrome, Lynch syndrome, pancreatic cystic tumors, etc.) for which there are recommendations for early screening [43-45]. Furthermore, it is considered that for patients with risk factors (chronic pancreatitis, new-onset diabetes mellitus, obesity, chronic alcohol consumption, smoking) early detection methods should be implemented in order to increase survival [46].

A model diagnostic method for pancreatic cancer should conclusively differentiate malignant from benign tumors, certify accurate tumor staging, and identify early-stage disease and pre-neoplastic conditions. Even though it takes years or decades for PanIN lesions to progress to pancreatic cancer, thus providing a time frame for diagnosis and a prospect for timely management, there are numerous challenges in the early detection of pancreatic cancer, including its asymptomatic nature, lack of specific biochemical tests or imaging variations $[47,48]$.

Primary screening using circulating biomarkers, followed by a confirmatory diagnosis based on imaging and pathological results could be the future strategy for diagnosing PC, although there is still a need for substantial effort in order to overcome limitations present in most studies. First, tumor heterogeneity has been recognized to obscure the chance for an accurate diagnosis. One or two biomarkers can narrowly deliver a comprehensive diagnosis of cancer in the era of precision medicine. Furthermore, selection of suboptimal samples can lead to misunderstanding concerning the diagnostic significance. Most samples in studies were collected from patients with advanced disease rather than from those with early disease. Third, any dynamic changes of biomarkers should be monitored after treatment, during the follow-up protocols, especially in high-risk populations [49,50].

The most pertinent recent techniques for biomarker discovery come from a systems biology approach [51]. Genomic studies, through genome sequencing, polymerase chain reactions (PCR) or fluorescence in situ hybridization (FISH), can lead to the detection of specific genetic biomarkers. Transcriptomics uses microarray profiling and RNA-sequencing for the discovery of expression biomarkers, while proteomics uses mass spectrometry 
as its main method for proteome characterization. Finally, metabolomics involves mass spectrometry of liquid chromatography for metabolite recognition $[52,53]$.

\subsubsection{Carbohydrate Antigens}

Presently, there are no validated biomarkers for PDAC detection, carbohydrate antigen (CA) 19-9 remaining the only approved biomarker used for progression and treatment response, but not for detection of pancreatic cancer, due to its low sensitivity and specificity [54]. Furthermore, $5-10 \%$ of Caucasians have Lewis-negative blood type, therefore do no produce CA 19-9. Other carbohydrate antigens, including CA 50, CA 72-4, CA 195, CA 242, CEA AND CA-125 have been broadly studied, but none showed superiority to CA 19-9 [55]. A combination of these biomarkers was proposed for better PC detection, but unfortunately, none are standardized or validated [56]. Additionally, an umbrella review of prognostic biomarkers for PDAC highlighted that a combination between CA 19-9 and C-reactive protein to albumin ration (CAR) or CA 19-9 and neutrophil to lymphocyte ratio (NRL) were supported by decidedly suggestive evidence, but the quality of the evidence was generally poor [57].

\subsubsection{Growth Factor Receptors}

Epidermal growth factor receptor (EGFR) has been one of the most studied receptors for targeted therapy in pancreatic cancer. It belongs to the epidermal growth receptor family, and its activation leads to signaling pathways that promote extensive tumor growth, prompt metastasis and overall high mortality [58]. Erlotinib, an EGFR tyrosine kinase inhibitor, represents the first and only approved EGFR targeted therapy (in combination with gemcitabine), which proved effective in increasing survival in PC [59]. Cetuximab, an anti-EGFR antibody, used in combination with radiotherapy has proved promising results in a phase II study [60].

Insulin-like growth factor-1 (IGF-1) and its receptor are also involved in the development of PC [61], through activating two main signaling pathways: phosphatidylinositol 3-kinase (PI3K)-Akt-mammalian target of rapamycin (mTOR) and RAS/RAF/MAPK thus leading to increased cell survival, proliferation, metastasis and drug resistance. Recent evidence also points to a critical role played by IGF-1 in the development and sustainability of the dense stroma characterizing PC [62], therefore, targeting this growth factor is a valid and promising therapeutic option. Dalotuzumab (MK-0464), a humanized monoclonal antibody directed to IGF-1 receptor, was demonstrated to amplify the gemcitabine effect on PC cells and inhibit the signaling pathways activated through IGF-1. Several phase I or II trials regarding drugs that target IGF-1 signaling were completed, terminated or are on-going [63-66], and even though there were some encouraging results, the overall outcome is still far from expected.

Transferrin receptor (TfR1) is another membrane protein which appears to be upregulated in over $93 \%$ of pancreatic tumors, playing an essential part in the progression of this type of tumor. The pathogenic mechanism behinds these findings is still unclear, but researchers have validated that TfR1 supports mitochondrial respiration and ROS generation in PC, which is indispensable for tumor growth. Given the importance of these studies, TfR1 has become an attractive therapeutic target $[67,68]$.

\subsubsection{Mesothelin}

Mesothelin (MSLN) is a membrane glycoprotein ordinarily expressed by peritoneum, pericardium or pleural mesothelial cells; studies have shown it can be highly expressed in many types of cancers $[69,70]$; its involvement in pancreatic cancer has also been summarized in a meta-analysis of 12 studies [71]. It was confirmed that mesothelin is expressed in pancreatic cancer cells, but not normal pancreatic cells, therefore, it could represent a potential biomarker for PC [72]. The meta-analysis also revealed a sensitivity of 0.71 and specificity of 0.88 , and suggested that using mesothelin in a combination panel with other biomarkers and a promising new tool for PC detection. Several trials involving 
complexes such as anti-mesothelin antibody (BAY-94 9343), SS1(dsFv)-PE38 (SS1P is a toxin that targets mesothelin) and MSLN tumor vaccine (CRS-207) have shown potential therapeutic value [73].

\subsubsection{Metabolites}

A process recognized as the Warburg effect, revealed nearly a century ago, taught us that cancer cells are capable of surviving and proliferating under oxygen and nutrientdeficient conditions [12]. They are also proficient in surviving in these harsh conditions through the process of metabolic reprogramming. This strategy is extremely important for pancreatic cancer, due to their extracellular environment characterized by hypoxia, substantial desmoplasia, and hypovascularization.

Recent technological advances have attracted more attention and interest in cancerassociated metabolic abnormalities and their potential diagnostic and therapeutic applications $[74,75]$. Accordingly, the uncovering of intermediates in metabolic reprogramming would point out an abnormal biochemical state of a patient and would suggest the existence of a malignancy. Iole et al. showed that serum palmitic acid could differentiate pancreatic cancer patients from healthy controls better than the traditional CA19-9 [76], Kobayashi et al. suggested a combination of four serum metabolites (xylitol, 1,5-anhydro-D-glucitol, histidine and inositol) for detection of chronic pancreatitis and PC, with good results [77]. Leichtle et al. [78] likewise described an association of serum amino acids which were able to discriminate patients with PC and chronic pancreatitis from healthy controls.

Given the important role that metabolic reprogramming plays in pancreatic cancer, including contributing to chemoresistance and radioresistance [79] researchers have tried to develop metabolism targeted therapy. For example, a phase I/II trial involving indoximod, an inhibitor of indoleamine 2,3-dioxygenase (IDO), which is an enzyme expressed in pancreatic cancer, was completed [80]. Another trial involving another IDO inhibitor is recruiting [81]. There are four more trials (recruiting or completed) involving amino acid metabolism targeted therapy in pancreatic cancer, and many others involving all metabolism pathways [79,82-84].

\subsubsection{Circulating Autoantibodies}

Granting little is presently known regarding the origin and pathogenesis behind circulating autoantibodies from the serum of patients with different types of cancer, recently, studies have indicated that they could represent potential biomarkers for the timely detection of cancer. It is already established that autoantibodies against tumor-associated antigens (for example, mutant tumor proteins, overexpressed proteins, or ectopic proteins) are created in numerous types of cancers, counting pancreatic cancer $[85,86]$. Anti-mucin 1 antibodies (MUC1) have become an important part of autoantibody research in PC. MUC1 is a glycoprotein expressed by the epithelial cells, membrane-bound, that is generally overexpressed in adenocarcinomas, including pancreatic cancer. Gold et al. [87], discovered a monoclonal antibody against MUC1 with 77\% sensitivity and 95\% specificity when discriminating normal controls from pancreatic cancer. Nevertheless, the diagnostic value of autoantibodies is significantly hindered by tumor heterogeneity.

\subsubsection{Matrix Metalloproteinases}

Matrix metalloproteinases (MMP) are endopeptidases that have the ability to degrade the extracellular matrix and therefore modulate TME. Their role in pancreatic cancer development has been established: MMP-1 (collagenase), MMP-9 (gelatinase-B), MMP-14 (MT1-MMP) and others are overexpressed in PC and have been proposed as biomarkers for this type of cancer [88]. MMP-14 also appears to be related to gemcitabine resistance [89]. Unfortunately, clinical trials involving MMP inhibitors, such as marimastat did not lead to the expected results; still, due to their essential role in TME behavior, researchers are still trying to develop MMP targeted therapy. 


\subsubsection{Plectin-1}

Plectin-1 (Plec1) is a protein with possible involvement in binding muscle proteins and anchoring microfilaments and microtubules to intermediate filaments. Its potential role as a biomarker for PC has been proposed. A study on mouse models of PC demonstrated that Plec1 was not only expressed in PDAC models, but also in preinvasive pancreatic intraepithelial neoplasia lesions and was also able to differentiate between chronic pancreatitis and pancreatic cancer [90]; another study supported these findings, indicating that Plec1 could also be a potential target for PDAC therapy [91]

\subsection{Biomarker Targeted Therapy Using Nanotechnology}

The field of precision oncology is rapidly expanding, as the use of targeted therapy becomes more advanced. In pancreatic cancer, fast development of different nanoprobes for diagnosis and therapy gives hope for increasing survival of these patients. Conjugation of nanoparticles with various biomarkers in order to increase imaging contrast or tumor accumulation has been tried with promising results (Table 1). It appears that in most cases, the process of conjugating a nanoparticle with a molecule that is overexpressed in PC leads to a more specific treatment method. Even though the biomarkers presented here are not all specific to $\mathrm{PC}$, their use might have potential for clinical implementation.

Table 1. Nanoparticles for biomarker targeted therapy and imaging in pancreatic cancer.

\begin{tabular}{cccc}
\hline Nanocomplex & Nanoparticle & Biomarker Targeted & Effect \\
\hline PTX-NP-anti CA 19-9 [92] & $\begin{array}{c}\text { Three block copolymer } \\
\text { organic nanoparticles }\end{array}$ & CA 19-9 & $\begin{array}{c}\text { Amplified PC cells uptake of the nanocomplex } \\
\text { and drug delivery of Paclitaxel }\end{array}$ \\
\hline SWCNT-EGF [9] & SWCNT & EGFR & Increased accumulation in PC cells \\
\hline EGF-curcumin liposomes [93] & liposome & EGFR & Increased cytotoxic effect of curcumin \\
\hline IONPs-IGF-1-DOX [10] & IONPs & IGF-1 & $\begin{array}{c}\text { Improved MRI contrast imaging } \\
\text { Augmented apoptosis of tumor cells }\end{array}$ \\
\hline SWCNT-IGF-1R antibody-Cy7 [94] & SWCNT & IGF-1 & Improved effects of PTT on tumor cells \\
\hline TfRscFv-Lip-6FAM-ODN [95] & liposome & TfR1 & Augmented gemcitabine transfer \\
\hline Anti-MSLN-PEG-Lipo-USPIO-Dox & liposome & MSLN & $\begin{array}{c}\text { Improved MRI contrast imaging } \\
\text { Augmented Doxorubicin efficacy }\end{array}$ \\
\hline uMUC-1-targeted CLIO-EPPT [97] & SPION & MUC-1 & Improved MRI imaging of tumor after treatment \\
\hline MNP-CUR [98] & Magnetic nanoparticles & MUC-1 & MUC-1 activity dropped up to 80\% \\
\hline MUC1-USPION [99] & SPION & MUC-1 & Improved MRI imaging \\
\hline POPE-SS-PEG [100] & liposome & MMP-9 & Increase in gemcitabine release at the tumor site \\
\hline Plectin-SPION-Cy7 [101] & SPION & Plectin-1 & Increased MRI contrast imaging and tumor \\
accumulation of the nanocomplex
\end{tabular}

CA 19-9 targeted therapy using nanotechnology was performed using nanoparticles conjugated with CA 19-9 antibodies and loaded with Paclitaxel (PTX). The complex was associated with ultrasound-mediated microbubble destruction (UMMD), a substance used for increased cellular uptake of the nanocomplex. Results were promising, showing an enhanced therapeutic efficacy of PTX [92].

Based on pancreatic tumor cells ability to overexpress EGFR, researchers have tried using nanotechnology for EGFR targeted therapy, mainly using EGFR's ligand, EGF. One study proved that by conjugating single wall carbon nanotubes (SWCNT) with EGF, the process will lead to an intense accumulation of the functionalized nanoparticles in a pancreatic adenocarcinoma (Panc-1) cell line [9]. Another study using EGF-conjugated liposomes and curcumin on different pancreatic cancer cell lines, led to an amplification in curcumin effect, namely cytotoxicity and tumor cell death [93].

Magnetic iron oxide nanoparticles (IONPs) were conjugated with recombinant human IGF-1, and along with doxorubicin as the chemotherapeutic, were administered to 
orthotopic xenograft models of PC. The novelty of the study was also supported by the use of numerous stromal cells in this model. The increased accumulation of the nanosystem was visible by MRI imaging. The study revealed increased apoptosis and inhibition of proliferation of the tumor cells after nanoparticle accumulation. Furthermore, there was no additional toxicity, proving that IGF-1R targeted therapy can represent a promising drug-delivery system [10]. Another team of researchers used SWCNT coupled with IGF-1R antibodies and an imaging agent (CY7) for the photothermal therapy (PTT) of PC. This novel system had a noteworthy curative effect, with minimal side effects, revealing an encouraging new therapeutic approach in the era of precision medicine [94]. Camp et al. used liposomal nanoparticles, conjugated with TfR antibody fragments, loaded with a wildtype p53 gene to improve gemcitabine delivery to PC cells. The p53 gene was used for its antineoplastic and proapoptotic proprieties. The nanocomplex improved the chemotherapy effect also presenting a potential role for gene therapy in this type of cancer [95].

The increasing demand in new therapeutic options for PC led to great progress in the field of theranostic nanomedicine. Nanoformulations are being now used for simultaneous imaging and therapy. Superparamagnetic iron oxide (SPIO) and ultrasmall superparamagnetic iron oxide (USPIO) are extensively used especially as MRI contrast agents, due to their advantageous characteristics such as contrast potency and low toxicity [103]. Based on these findings, Deng et al. used liposomes loaded with USPIOs, doxorubicin and an anti-MSLN antibody on both Panc-1 cell lines and mouse models of PC. Assembly of the nanoformulation was done by treating the anti MSLN antibody with a reagent and incubating it with the PEGylated liposomes, loaded with the chemotherapy agent and USPIOs (Figure 3). The nanosystem improved imaging of the tumor cells and increased the therapeutic efficacy of DOX, thus, offering a dual benefit for the use of these types of formulations [96].

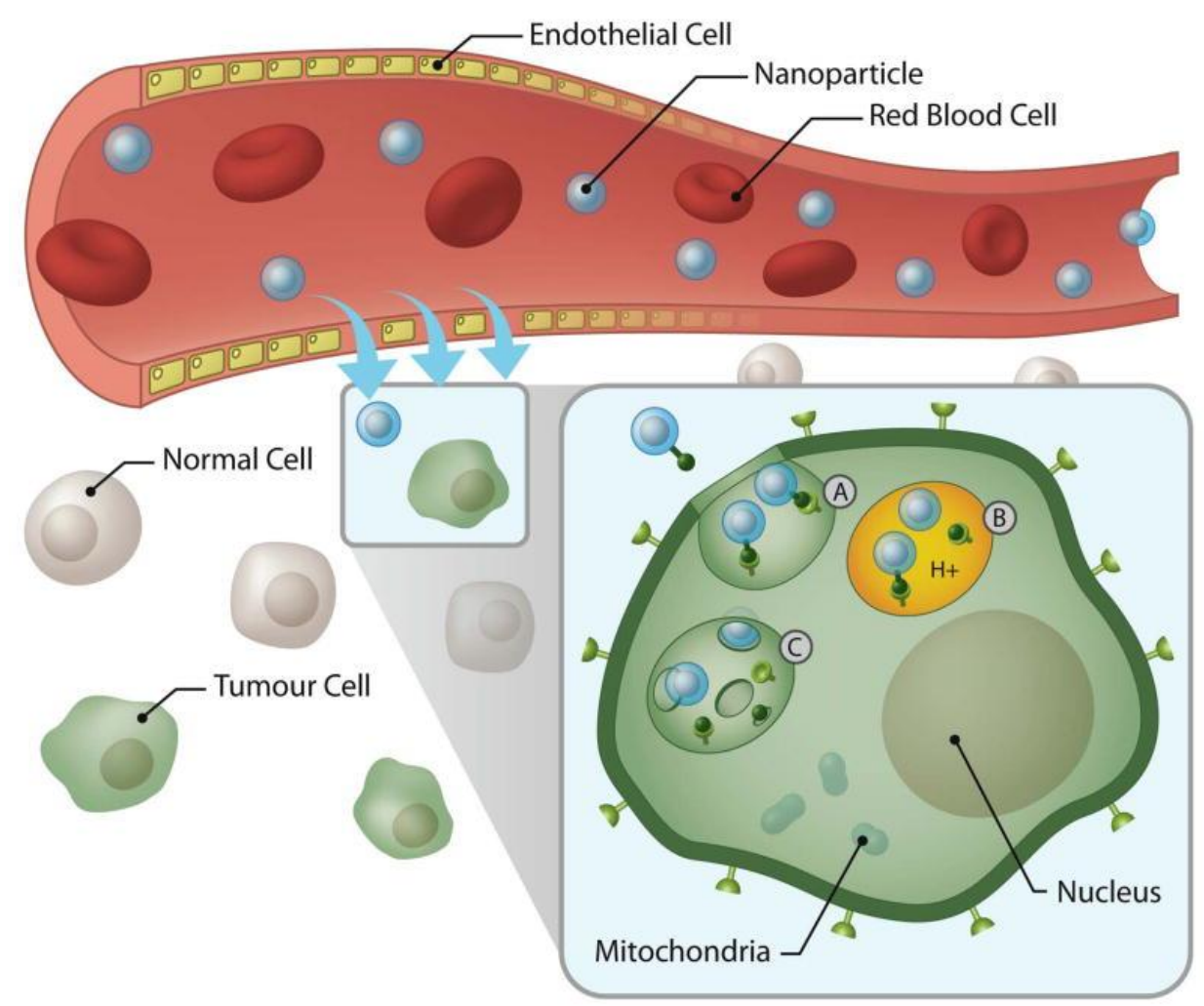

Figure 3. Delivery of magnetic nanoparticles, using active targeting, the process being facilitated the leaky vasculature. A: nanoparticle internalization leading to endosome development; B: High osmotic pressure and swelling of the endosome; C: release of the conjugated nanoparticles. Reprinted with permission from [104]. 
A team of researchers have tried to manipulate glucose metabolism using nanoparticles in different PC cell lines, afterwards submitting them to photodynamic therapy [105]. Their results were promising, suggesting that a better understanding of the metabolic reprogramming in PC will definitely lead to developing new and improved therapeutic strategies.

Regarding MUC-1 as a biomarker and the use of nanotechnology, superparamagnetic iron oxide nanoparticles were conjugated with underglycosylated mucin-1 tumor-specific antigen (uMUC-1), in order to increase the quality of tumor imaging in treatment follow-up, on a orthotopic model of human pancreatic cancer line. Using MRI and near infrared optical imaging, Medarova et al. [97] demonstrated that the nanocomplex could provide a highresolution, nonionizing and fast imaging method for detailed assessment of tumor response to PC treatment. A different team of researchers suggested a possible use for magnetic nanoparticles loaded with curcumin on human pancreatic cancer cell lines, by targeting mucin-1. Muc-1 activity in this scenario was reported to have dropped up to $80 \%$ after treatment using the nanoformulation described [98]. Zou et al. used SPIO nanoparticles conjugated with MUC-1 in tumor bearing mice. The conjugated nanooparticles managed to increase contrast in MRI imaging both in vivo and in vitro [99].

Another group of investigators formulated a nanoparticle responsive to MMP-9, that had the ability to trigger gemcitabine release from the nanocomplex in tumor bearing mice in the extracellular matrix of the TME. To ensure proper visualization of the nanoparticles administered, they were infused with carboxyfluorescein and confocal fluorescence microscopy was performed (Figure 4). The authors proved that overexpression of MMP-9 in the TME has the ability to modulate drug release [100].

Wang et al. demonstrated that administration of SPIO nanoparticles along with bovine serum albumin, targeting plectin-1 expressing pancreatic tumor cells improved MRI contrast, revealing a potential role for Plec1 as target for PC imaging [101].Based on these findings, biomarker targeted imaging was also attempted by Chen et al. [102]: they used plectin- 1 antibody conjugated SPION nanoparticles and Cy7 as a contrast agent (Plectin-SPION-Cy7) on PC cell lines (MIA PaCa2, Panc-1, XPA-1 and BxPC3) that expressed plectin-1, with MIA PaCa2 and Panc-1 having the highest expression; the probes were then visualized through MRI and confocal microscopy. The study revealed high accumulation of conjugated nanoparticles at the tumor site and improved imaging contrast after administration of the nanocomplex.

As different biomarkers, such as EGFR, IGF-1R, plectin and others like urokinase plasminogen activator or zinc transporter-4 are overexpressed on the tumor cells or on different TME cells, they play a critical role in targeted therapy (Figure 4). The use of nanoparticles in pancreatic cancer is definitively beneficial, and, as studies mentioned above demonstrate, further combining them with potential biomarkers improved therapeutic efficacy and imaging. An extended review on nanomedicine implementation for pancreatic cancer highlights years of research that led to promising results in this field [30]. Our addition is represented by taking one step further and adding specific or non-specific biomarkers onto the nanoparticles used. As PC is highly resistant to chemotherapy, there is a clear need for methods that can overcome this impediment. Researchers proved that by using different nanocomplexes conjugated with biomarkers $[9,92,93]$ the transfer or accumulation of therapy drugs such as curcumin, gemcitabine or paclitaxel in PC cancer cells is augmented; this effect is also useful in reducing systemic chemotherapy toxicity, which often contributes to the low quality of life of the patients. This effect is detrimental for the desired purpose of all oncologic treatments, to improve therapy results with less toxicity. Seeing as a nanocomplex, namely, Abraxane [5], has already been approved for PC treatment, there is hope for other conjugated nanoparticles to be accepted for use.

The use of nanotechnology is also beneficial in manipulating the tumor microenvironment, as highlighted by several reviews $[8,22,23]$, seeing as TME is an important obstacle in drug delivery. Nanoparticle targeted therapy using MMP as a biomarker was successfully 
used for gemcitabine release in the extracellular matrix of PC [100], strengthening the usefulness of combining therapy methods for augmented results.

Another obstacle in PC therapy is represented by imaging follow up and the use of imaging methods for visualization of the nanoparticles used in order to properly characterize therapy response. The most common nanoparticles used for improving imaging contrast are SPIO and USPIO, with promising results due to their characteristics $[96,99,101,102]$. Research combined imaging with therapy methods [96,103], further demonstrating the multitude of benefits in using nanotechnology in PC treatment. The use of photodynamic therapy also holds promise for better outcomes in PC [104], but obstacles regarding its side effects and potential toxicity are still an impediment for clinical use [71]. Other potential benefits for improving imaging methods in PC is rapid detection as already mentioned, as it takes years for PanIN lesions to develop into PC, and unfortunately there also no approved biomarkers for early detection. Merging biomarkers with nanoparticles for early detection through imaging methods could represent a novel approach.

The main predicament of all these studies is the lack of clinical implementation due to limitations. There are still unknown factors that need to be taken into account, such as nanoparticle accumulation and elimination, systemic effects, so studies should also focus on understanding the pharmacokinetics of the nanoconjugates used, in order to safely use them.

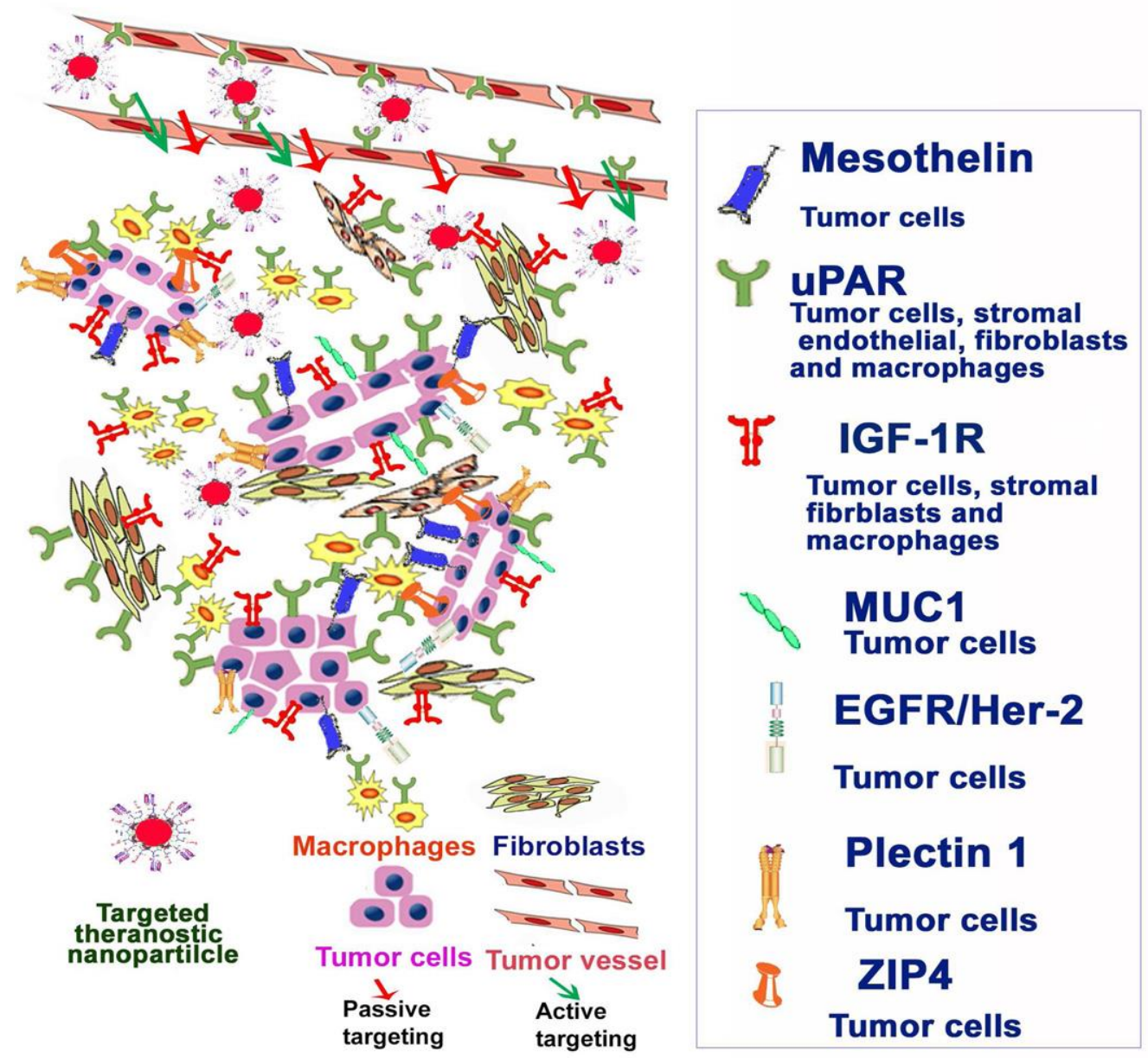

Figure 4. Biomarkers used for their potential role in nanomediated therapy. Abbreviations: uPARUrokinase Plasminogen Activator, ZIP4—zinc transporter 4. Reprinted with permission from [105].

\subsection{Prognostic Value of Biomarkers in Pancreatic Cancer}

Most patients diagnosed with this type of cancer are not suitable for curative (surgical) treatment and for the ones that are, there are still questions whether there is real and equal 
benefit for all. [106]. The lack of prognostic tools in PC makes it all the more difficult for clinicians to adhere to the concept of personalized medicine. Still, aside from their crucial role in therapy and targeted imaging, some biomarkers have been demonstrated to play an important part in the prognosis of PC, following surgical treatment. CA 19-9 has limited prognostic value, with its postoperative value seeming more valuable than its preoperative one $[107,108]$. An immunohistochemical analysis of pancreatic tissues from 137 patients following pancreatic resection revealed that two biomarkers, namely MUC1 and MSLN had highly prognostic value, predicting survival better than the standard pathologic features used in clinical practice (resections margins, grade, tumor size, lymph node invasion) [109]. Regarding growth factors and their receptors, EGFR status was reported to be associated with the development of metastasis in PC; its high expression was connected to liver metastasis in particular. The study suggested its potential use as a prognostic for metastatic disease [110]. Another study on 122 patients with resected PC found that IGF1R and IGF binding protein-3 (IGFBP3) and their expression is correlated with histological tumor differentiation; immunohistochemical analysis proved that IGF 1 is expressed in advanced stages of PC, while IGFBP3 is downregulated in these stages; these findings suggest a potential use for IGF and its receptor as a prognostic marker for patients undergoing curative treatment [111]. Lin et al. demonstrated the use of transferrin as a prognostic marker for survival in patients with negative CA 19-9 PDAC. A proteomic technique was used in this study to show that Trf was linked with survival and tumor differentiation after curative surgery [112]. All studies showed promising results for better predicting outcomes after therapy in PC patients, but there are impediments to clinical application, as larger cohorts are needed to validate their value.

\section{Conclusions}

Pancreatic cancer remains a disease with poor prognosis, in spite of advances in research. The pancreatic tumor microenvironment plays an essential role in therapy response, cell proliferation, neoplastic development and metastasis and targeted therapy needs to overcome this hurdle as well in order to properly destroy the tumor cells. Nanotechnology, through its numerous advantages, offers faith for developing new and enhanced therapeutic schemes, by permitting nanoparticles to better direct and release chemotherapy medication directly into the tumor site. Biomarkers, besides their important role in the diagnosis and prognosis of any disease, could also play an important part in directed therapy. Most nanoparticle targeted therapy using biomarkers specific or non-specific for PC has shown that by using specific ligands, tumors are better visualized and treated. Granting there is still a long way until clinical implementation, the research done so far has contributed vastly to the advancement in the field of precision medicine.

Author Contributions: C.M.G. contributed to the conceptualization, writing and editing of the manuscript. L.M., D.C. and M.F. contributed to the writing and editing of the manuscript. T.M. contributed to the conceptualization, writing and editing of the manuscript. All authors have read and agreed to the published version of the manuscript.

Funding: The authors wish to acknowledge financial support from the "Iuliu Hatieganu" University of Medicine and Pharmacy, Cluj-Napoca, Romania, grant no. 1032/26/13.01.2021. This work was also supported by the Romanian National Authority for Scientific Research and Innovation, CNCS-UEFISCDI, project numbers PN-III-P2-2.1-PED-2019-0844, PN-III-P2-2.1-PED-2019-0997, PNIII-P2-2.1-PED-2019-3373.

Institutional Review Board Statement: Not applicable.

Informed Consent Statement: Not applicable.

Conflicts of Interest: The authors declare no conflict of interest. 


\section{References}

1. Siegel, R.L.; Miller, K.D.; Jemal, A. Cancer statistics, 2017. CA A Cancer J. Clin. 2017, 67, 7-30. [CrossRef]

2. Rahib, L.; Smith, B.D.; Aizenberg, R.; Rosenzweig, A.B.; Fleshman, J.M.; Matrisian, L.M. Projecting cancer incidence and deaths to 2030: The unexpected burden of thyroid, liver, and pancreas cancers in the United States. Cancer Res. 2014, 74, $2913-2921$. [CrossRef]

3. Rebelo, A.; Molpeceres, J.; Rijo, P.; Reis, C. Pancreatic Cancer Therapy Review: From Classic Therapeutic Agents to Modern Nanotechnologies. Curr. Drug Metab. 2017, 18, 346-359. [CrossRef]

4. Kleeff, J.; Reiser, C.; Hinz, U.; Bachmann, J.; Debus, J.; Jaeger, D.; Friess, H.; Büchler, M.W. Surgery for Recurrent Pancreatic Ductal Adenocarcinoma. Ann. Surg. 2007, 245, 566-572. [CrossRef] [PubMed]

5. Kim, M.P.; Gallick, G.E. Gemcitabine Resistance in Pancreatic Cancer: Picking the Key Players. Clin. Cancer Res. 2008, 14, 1284-1285. [CrossRef] [PubMed]

6. Liu, X.; Situ, A.; Kang, Y.; Villabroza, K.R.; Liao, Y.; Chang, C.H.; Donahue, T.; Nel, A.E.; Meng, H. Irinotecan Delivery by Lipid-Coated Mesoporous Silica Nanoparticles Shows Improved Efficacy and Safety over Liposomes for Pancreatic Cancer. ACS Nano 2016, 10, 2702-2715. [CrossRef] [PubMed]

7. Grapa, C.M.; Mocan, T.; Gonciar, D.; Zdrehus, C.; Mosteanu, O.; Pop, T.; Mocan, L. Epidermal Growth Factor Receptor and Its Role in Pancreatic Cancer Treatment Mediated by Nanoparticles. Int. J. Nanomed. 2019, 14, 9693-9706. [CrossRef]

8. McCarroll, J.; Teo, J.; Boyer, C.; Goldstein, D.; Kavallaris, M.; Phillips, P.A. Potential applications of nanotechnology for the diagnosis and treatment of pancreatic cancer. Front. Physiol. 2014, 5, 2. [CrossRef] [PubMed]

9. Karmakar, A.; Iancu, C.; Bartos, D.M.; Mahmood, M.W.; Ghosh, A.; Xu, Y.; Dervishi, E.; Collom, S.L.; Khodakovskaya, M.; Mustafa, T.; et al. Raman spectroscopy as a detection and analysis tool for in vitro specific targeting of pancreatic cancer cells by EGF-conjugated, single-walled carbon nanotubes. J. Appl. Toxicol. 2011, 32, 365-375. [CrossRef]

10. Zhou, H.; Qian, W.; Uckun, F.M.; Wang, L.; Wang, Y.A.; Chen, H.; Kooby, D.; Yu, Q.; Lipowska, M.; Staley, C.A.; et al. IGF1 Receptor Targeted Theranostic Nanoparticles for Targeted and Image-Guided Therapy of Pancreatic Cancer. ACS Nano 2015, 9 , 7976-7991. [CrossRef] [PubMed]

11. Feig, C.; Gopinathan, A.; Neesse, A.; Chan, D.S.; Cook, N.; Tuveson, D.A. The Pancreas Cancer Microenvironment. Clin. Cancer Res. 2012, 18, 4266-4276. [CrossRef] [PubMed]

12. Hanahan, D.; Weinberg, R.A. Hallmarks of Cancer: The Next Generation. Cell 2011, 144, 646-674. [CrossRef] [PubMed]

13. Joyce, J.A. Therapeutic targeting of the tumor microenvironment. Cancer Cell 2005, 7, 513-520. [CrossRef] [PubMed]

14. Takahashi, K.; Ehata, S.; Koinuma, D.; Morishita, Y.; Soda, M.; Mano, H.; Miyazono, K. Pancreatic tumor microenvironment confers highly malignant properties on pancreatic cancer cells. Oncogene 2018, 37, 2757-2772. [CrossRef]

15. Thomas, D.; Radhakrishnan, P. Tumor-stromal crosstalk in pancreatic cancer and tissue fibrosis. Mol. Cancer 2019, 18, 1-15. [CrossRef]

16. Mews, P.; Phillips, P.; Fahmy, R.; Korsten, M.; Pirola, R.; Wilson, J.; Apte, M. Pancreatic stellate cells respond to inflammatory cytokines: Potential role in chronic pancreatitis. Gut 2002, 50, 535-541. [CrossRef] [PubMed]

17. Erkan, M.; Michalski, C.W.; Rieder, S.; Reiser-Erkan, C.; Abiatari, I.; Kolb, A.; Giese, N.A.; Esposito, I.; Friess, H.; Kleeff, J. The activated stroma index is a novel and independent prognostic marker in pancreatic ductal adenocarcinoma. Clin. Gastroenterol. Hepatol. 2008, 6, 1155-1161. [CrossRef]

18. Momcilovic, M.; Shackelford, D.B. Imaging Cancer Metabolism. Biomol. Ther. 2018, 26, 81-92. [CrossRef] [PubMed]

19. Chen, S.; Chen, X.; Shan, T.; Ma, J.; Lin, W.; Li, W.; Kang, Y. MiR-21-mediated Metabolic Alteration of Cancer-associated Fibroblasts and Its Effect on Pancreatic Cancer Cell Behavior. Int. J. Biol. Sci. 2018, 14, 100-110. [CrossRef]

20. Bachem, M.G.; Schneider, E.; Groß, H.; Weidenbach, H.; Schmid, R.M.; Menke, A.; Siech, M.; Beger, H.; Grünert, A.; Adler, G. Identification, culture, and characterization of pancreatic stellate cells in rats and humans. Gastroenterology 1998, 115, 421-432. [CrossRef]

21. Stopa, K.B.; Kusiak, A.A.; Szopa, M.D.; Ferdek, P.E.; Jakubowska, M.A. Pancreatic Cancer and Its Microenvironment-Recent Advances and Current Controversies. Int. J. Mol. Sci. 2020, 21, 3218. [CrossRef]

22. Miao, L.; Lin, C.M.; Huang, L. Stromal barriers and strategies for the delivery of nanomedicine to desmoplastic tumors. J. Control. Release 2015, 219, 192-204. [CrossRef]

23. Meng, H.; Nel, A.E. Use of nano engineered approaches to overcome the stromal barrier in pancreatic cancer. Adv. Drug Deliv. Rev. 2018, 130, 50-57. [CrossRef]

24. Kuen, J. Influence of 3D Tumor Cell/Fibroblast Co-Culture on Monocyte Differentiation and Tumor Progression in Pancreatic Cancer. Ph.D. Thesis, Julius-Maximilians University, Würzburg, Germany, 2017.

25. van Mackelenbergh, M.G.; Stroes, C.I.; Spijker, R.; van Eijck, C.H.; Wilmink, J.W.; Bijlsma, M.F.; van Laarhoven, H.W. Clinical trials targeting the stroma in pancreatic cancer: A systematic review and meta-analysis. Cancers 2019, 11, 588. [CrossRef]

26. Olive, K.P.; Jacobetz, M.A.; Davidson, C.J.; Gopinathan, A.; McIntyre, D.; Honess, D.; Madhu, B.; Goldgraben, M.A.; Caldwell, M.E.; Allard, D.; et al. Inhibition of Hedgehog Signaling Enhances Delivery of Chemotherapy in a Mouse Model of Pancreatic Cancer. Science 2009, 324, 1457-1461. [CrossRef]

27. Patra, C.R.; Bhattacharya, R.; Mukhopadhyay, D.; Mukherjee, P. Fabrication of gold nanoparticles for targeted therapy in pancreatic cancer. Adv. Drug Deliv. Rev. 2010, 62, 346-361. [CrossRef] [PubMed] 
28. Maeda, H. The enhanced permeability and retention (EPR) effect in tumor vasculature: The key role of tumor-selective macromolecular drug targeting. Adv. Enzym. Regul. 2001, 41, 189-207. [CrossRef]

29. Yu, B.; Zhao, X.; Lee, L.J.; Lee, R.J. Targeted Delivery Systems for Oligonucleotide Therapeutics. AAPS J. 2009, 11, 195-203. [CrossRef] [PubMed]

30. El-Zahaby, S.A.; Elnaggar, Y.S.; Abdallah, O.Y. Reviewing two decades of nanomedicine implementations in targeted treatment and diagnosis of pancreatic cancer: An emphasis on state of art. J. Control. Release 2019, 293, 21-35. [CrossRef] [PubMed]

31. Muntimadugu, E.; Kommineni, N.; Khan, W. Exploring the Potential of Nanotherapeutics in Targeting Tumor Microenvironment for Cancer Therapy. Pharmacol. Res. 2017, 126, 109-122. [CrossRef]

32. Martinelli, C.; Pucci, C.; Ciofani, G. Nanostructured carriers as innovative tools for cancer diagnosis and therapy. APL Bioeng. 2019, 3, 011502. [CrossRef] [PubMed]

33. Au, M.; Emeto, T.I.; Power, J.; Vangaveti, V.N.; Lai, H.C. Emerging Therapeutic Potential of Nanoparticles in Pancreatic Cancer: A Systematic Review of Clinical Trials. Biomedicines 2016, 4, 20. [CrossRef] [PubMed]

34. Thota, R.; Pauff, J.M.; Berlin, J.D. Treatment of metastatic pancreatic adenocarcinoma: A review. Oncology 2014, 28 , 70-74. [PubMed]

35. Chawla, S.P.; Chua, V.S.; Fernandez, L.; Quon, D.; Blackwelder, W.C.; Gordon, E.M.; Hall, F.L. Advanced Phase I/II Studies of Targeted Gene Delivery In Vivo: Intravenous Rexin-G for Gemcitabine-resistant Metastatic Pancreatic Cancer. Mol. Ther. 2010, 18, 435-441. [CrossRef]

36. Galanis, E.; Carlson, S.K.; Foster, N.R.; Lowe, V.; Quevedo, F.; McWilliams, R.R.; Grothey, A.; Jatoi, A.; Alberts, S.R.; Rubin, J. Phase I Trial of a Pathotropic Retroviral Vector Expressing a Cytocidal Cyclin G1 Construct (Rexin-G) in Patients With Advanced Pancreatic Cancer. Mol. Ther. 2008, 16, 979-984. [CrossRef] [PubMed]

37. Gordon, E.; López, F.; Cornelio, G.; Lorenzo, C.; Levy, J.; Reed, R.; Liu, L.; Bruckner, H.; Hall, F. Pathotropic nanoparticles for cancer gene therapy Rexin-GTM IV: Three-year clinical experience. Int. J. Oncol. 2006, 29, 1053-1064. [CrossRef]

38. Hamaguchi, T.; Kato, K.; Yasui, H.; Morizane, C.; Ikeda, M.; Ueno, H.; Muro, K.; Yamada, Y.; Okusaka, T.; Shirao, K.; et al. A phase I and pharmacokinetic study of NK105, a paclitaxel-incorporating micellar nanoparticle formulation. Br. J. Cancer 2007, 97, 170-176. [CrossRef]

39. Stathopoulos, G.P.; Boulikas, T.; Vougiouka, M.; Rigatos, S.K.; Stathopoulos, J.G. Liposomal cisplatin combined with gemcitabine in pretreated advanced pancreatic cancer patients: A phase I-II study. Oncol. Rep. 2006, 15, 1201-1204. [CrossRef]

40. Han, X.; Li, Y.; Xu, Y.; Zhao, X.; Zhang, Y.; Yang, X.; Wang, Y.; Zhao, R.; Anderson, G.J.; Zhao, Y.; et al. Reversal of pancreatic desmoplasia by re-educating stellate cells with a tumour microenvironment-activated nanosystem. Nat. Commun. 2018, 9, 1-18. [CrossRef]

41. Cun, X.; Chen, J.; Li, M.; He, X.; Tang, X.; Guo, R.; Deng, M.; Li, M.; Zhang, Z.; He, Q. Tumor-Associated Fibroblast-Targeted Regulation and Deep Tumor Delivery of Chemotherapeutic Drugs with a Multifunctional Size-Switchable Nanoparticle. ACS Appl. Mater. Interfaces 2019, 11, 39545-39559. [CrossRef]

42. Zinger, A.; Koren, L.; Adir, O.; Poley, M.; Alyan, M.; Yaari, Z.; Noor, N.; Krinsky, N.; Simon, A.; Gibori, H.; et al. Collagenase Nanoparticles Enhance the Penetration of Drugs into Pancreatic Tumors. ACS Nano 2019, 13, 11008-11021. [CrossRef] [PubMed]

43. Kenner, B.J.; Chari, S.T.; Cleeter, D.F.; Go, V.L.W. Early Detection of Sporadic Pancreatic Cancer. Pancreas 2015, 44, 686-692. [CrossRef] [PubMed]

44. Canto, M.I.; Harinck, F.; Hruban, R.H.; Offerhaus, G.J.; Poley, J.-W.; Kamel, I.; Nio, Y.; Schulick, R.S.; Bassi, C.; Kluijt, I.; et al. International Cancer of the Pancreas Screening (CAPS) Consortium summit on the management of patients with increased risk for familial pancreatic cancer. Gut 2012, 62, 339-347. [CrossRef]

45. Grocock, C.J.; Vitone, L.J.; Harcus, M.J.; Neoptolemos, J.; Raraty, M.G.T.; Greenhalf, W. Familial pancreatic cancer: A review and latest advances. Adv. Med. Sci. 2007, 52, 52.

46. Henrikson, N.B.; Bowles, E.J.A.; Blasi, P.R.; Morrison, C.C.; Nguyen, M.; Pillarisetty, V.G.; Lin, J.S. Screening for pancreatic cancer: Updated evidence report and systematic review for the US Preventive Services Task Force. JAMA 2019, 322, 445-454. [CrossRef]

47. Pereira, S.P.; Oldfield, L.; Ney, A.; A Hart, P.; Keane, M.G.; Pandol, S.J.; Li, D.; Greenhalf, W.; Jeon, C.Y.; Koay, E.J.; et al. Early detection of pancreatic cancer. Lancet Gastroenterol. Hepatol. 2020, 5, 698-710. [CrossRef]

48. Hart, P.A.; Chari, S.T. Is Screening for Pancreatic Cancer in High-Risk Individuals One Step Closer or a Fool's Errand? Clin. Gastroenterol. Hepatol. 2019, 17, 36-38. [CrossRef]

49. Tonack, S.; Jenkinson, C.; Cox, T.; Elliott, V.; E Jenkins, R.; Kitteringham, N.R.; Greenhalf, W.; Shaw, V.; Michalski, C.W.; Friess, H.; et al. iTRAQ reveals candidate pancreatic cancer serum biomarkers: Influence of obstructive jaundice on their performance. $\mathrm{Br}$. $\mathrm{J}$. Cancer 2013, 108, 1846-1853. [CrossRef] [PubMed]

50. Nie, S.; Lo, A.; Wu, J.; Zhu, J.; Tan, Z.; Simeone, D.M.; Anderson, M.A.; Shedden, K.A.; Ruffin, M.T.; Lubman, D.M. Glycoprotein Biomarker Panel for Pancreatic Cancer Discovered by Quantitative Proteomics Analysis. J. Proteome Res. 2014, 13, 1873-1884. [CrossRef]

51. Scaros, O.; Fisler, R. Biomarker technology roundup: From discovery to clinical applications, a broad set of tools is required to translate from the lab to the clinic. Biotechniques 2005, 38, S30-S32. [CrossRef]

52. Rifai, N.; A Gillette, M.; A Carr, S. Protein biomarker discovery and validation: The long and uncertain path to clinical utility. Nat. Biotechnol. 2006, 24, 971-983. [CrossRef] 
53. Deyati, A.; Younesi, E.; Hofmann-Apitius, M.; Novac, N. Challenges and opportunities for oncology biomarker discovery. Drug Discov. Today 2013, 18, 614-624. [CrossRef] [PubMed]

54. E Poruk, K.; Z Gay, D.; Brown, K.; D Mulvihill, J.; M Boucher, K.; L Scaife, C.; A Firpo, M.; J Mulvihill, S. The clinical utility of CA 19-9 in pancreatic adenocarcinoma: Diagnostic and prognostic updates. Curr. Mol. Med. 2013, 13, 340-351.

55. Bünger, S.; Laubert, T.; Roblick, U.J.; Habermann, J.K. Serum biomarkers for improved diagnostic of pancreatic cancer: A current overview. J. Cancer Res. Clin. Oncol. 2010, 137, 375-389. [CrossRef]

56. Liao, Q.; Zhao, Y.-P.; Yang, Y.-C.; Li, L.-J.; Long, X.; Han, S.-M. Combined detection of serum tumor markers for differential diagnosis of solid lesions located at the pancreatic head. Hepatobiliary Pancreat. Dis. Int. 2007, 6, 641-645.

57. Wang, Y.; Zhong, X.; Zhou, L.; Lu, J.; Jiang, B.; Liu, C.; Guo, J. Prognostic Biomarkers for Pancreatic Ductal Adenocarcinoma: An Umbrella Review. Front. Oncol. 2020, 10, 1466. [CrossRef] [PubMed]

58. Yamanaka, Y.; Friess, H.; Kobrin, M.S.; Buchler, M.; Beger, H.G.; Korc, M. Coexpression of epidermal growth factor receptor and ligands in human pancreatic cancer is associated with enhanced tumor aggressiveness. Anticancer. Res. 1993, 13, 565-569. [PubMed]

59. Philip, P.A.; Lutz, M.P. Targeting Epidermal Growth Factor Receptor-Related Signaling Pathways in Pancreatic Cancer. Pancreas 2015, 44, 1046-1052. [CrossRef]

60. Rembielak, A.; Jain, P.; Jackson, A.; Green, M.; Santorelli, G.R.; Whitfield, G.; Crellin, A.; Garcia-Alonso, A.; Radhakrishna, G.; Cullen, J.; et al. Phase II Trial of Cetuximab and Conformal Radiotherapy Only in Locally Advanced Pancreatic Cancer with Concurrent Tissue Sampling Feasibility Study. Transl. Oncol. 2014, 7, 55-64. [CrossRef]

61. Rieder, S.; W Michalski, C.; Friess, H. Insulin-like growth factor signaling as a therapeutic target in pancreatic cancer. Anti-Cancer Agents Med. Chem. 2011, 11, 427-433. [CrossRef]

62. Mutgan, A.C.; Besikcioglu, H.E.; Wang, S.; Friess, H.; Ceyhan, G.O.; Demir, I.E. Insulin/IGF-driven cancer cell-stroma crosstalk as a novel therapeutic target in pancreatic cancer. Mol. Cancer 2018, 17, 1-11. [CrossRef]

63. Kindler, H.; Richards, D.; Garbo, L.; Garon, E.; Stephenson Jr, J.; Rocha-Lima, C.; Safran, H.; Chan, D.; Kocs, D.; Galimi, F. A randomized, placebo-controlled phase 2 study of ganitumab (AMG 479) or conatumumab (AMG 655) in combination with gemcitabine in patients with metastatic pancreatic cancer. Ann. Oncol. 2012, 23, 2834-2842. [CrossRef]

64. Tabernero, J.; Chawla, S.P.; Kindler, H.; Reckamp, K.; Chiorean, E.G.; Azad, N.S.; Lockhart, A.C.; Hsu, C.-P.; Baker, N.F.; Galimi, F.; et al. Anticancer activity of the type I insulin-like growth factor receptor antagonist, ganitumab, in combination with the death receptor 5 agonist, conatumumab. Target. Oncol. 2015, 10, 65-76. [CrossRef]

65. Philip, P.A.; Goldman, B.; Ramanathan, R.K.; Lenz, H.; Lowy, A.M.; Whitehead, R.P.; Wakatsuki, T.; Iqbal, S.; Gaur, R.; Benedetti, J.K. Dual blockade of epidermal growth factor receptor and insulin-like growth factor receptor-1 signaling in metastatic pancreatic cancer: Phase Ib and randomized phase II trial of gemcitabine, erlotinib, and cixutumumab versus gemcitabine plus erlotinib (SWOG S0727). Cancer 2014, 120, 2980-2985.

66. Braghiroli, M.I.; Ferrari, A.C.R.D.C.; Pfiffer, T.E.; Alex, A.K.; Nebuloni, D.; Carneiro, A.S.; Caparelli, F.; Senna, L.; Lobo, J.; Hoff, P.M.; et al. Phase II trial of metformin and paclitaxel for patients with gemcitabine-refractory advanced adenocarcinoma of the pancreas. Ecancermedicalscience 2015, 9, 563. [CrossRef] [PubMed]

67. Ryschich, E.; Huszty, G.; Knaebel, H.; Hartel, M.; Büchler, M.; Schmidt, J. Transferrin receptor is a marker of malignant phenotype in human pancreatic cancer and in neuroendocrine carcinoma of the pancreas. Eur. J. Cancer 2004, 40, 1418-1422. [CrossRef] [PubMed]

68. Jeong, S.M.; Hwang, S.; Seong, R.H. Transferrin receptor regulates pancreatic cancer growth by modulating mitochondrial respiration and ROS generation. Biochem. Biophys. Res. Commun. 2016, 471, 373-379. [CrossRef] [PubMed]

69. Ordóñez, N.G. Application of Mesothelin Immunostaining in Tumor Diagnosis. Am. J. Surg. Pathol. 2003, 27, 1418-1428. [CrossRef]

70. Frierson Jr, H.F.; Moskaluk, C.A.; Powell, S.M.; Zhang, H.; Cerilli, L.A.; Stoler, M.H.; Cathro, H.; Hampton, G.M. Large-scale molecular and tissue microarray analysis of mesothelin expression in common human carcinomas. Hum. Pathol. 2003, 34, 605-609. [CrossRef]

71. Zhu, L.; Liu, Y.; Chen, G. Diagnostic value of mesothelinin pancreatic cancer: A meta-analysis. Int. J. Clin. Exp. Med. 2014, 7, 4000-4007.

72. Scholler, N.; Fu, N.; Yang, Y.; Ye, Z.; Goodman, G.E.; Hellström, K.E.; Hellström, I. Soluble member(s) of the mesothelin/megakaryocyte potentiating factor family are detectable in sera from patients with ovarian carcinoma. Proc. Natl. Acad. Sci. USA 1999, 96, 11531-11536. [CrossRef]

73. Kelly, R.J.; Sharon, E.; Pastan, I.; Hassan, R. Mesothelin-Targeted Agents in Clinical Trials and in Preclinical Development: Table Mol. Cancer Ther. 2012, 11, 517-525. [CrossRef] [PubMed]

74. Garber, K. Energy Boost: The Warburg Effect Returns in a New Theory of Cancer. J. Natl. Cancer Inst. 2004, 96, 1805-1806. [CrossRef]

75. Spratlin, J.L.; Serkova, N.J.; Eckhardt, S.G. Clinical Applications of Metabolomics in Oncology: A Review. Clin. Cancer Res. 2009, 15, 431-440. [CrossRef]

76. di Gangi, I.M.; Mazza, T.; Fontana, A.; Copetti, M.; Fusilli, C.; Ippolito, A.; Mattivi, F.; Latiano, A.; Andriulli, A.; Vrhovsek, U.; et al. Metabolomic profile in pancreatic cancer patients: A consensus-based approach to identify highly discriminating metabolites. Oncotarget 2016, 7, 5815-5829. [CrossRef] 
77. Sakai, A.; Suzuki, M.; Kobayashi, T.; Nishiumi, S.; Yamanaka, K.; Hirata, Y.; Nakagawa, T.; Azuma, T.; Yoshida, M. Pancreatic cancer screening using a multiplatform human serum metabolomics system. Biomark. Med. 2016, 10, 577-586. [CrossRef] [PubMed]

78. Leichtle, A.B.; Ceglarek, U.; Weinert, P.; Nakas, C.; Nuoffer, J.-M.; Kase, J.; Conrad, T.; Witzigmann, H.; Thiery, J.; Fiedler, G.M. Pancreatic carcinoma, pancreatitis, and healthy controls: Metabolite models in a three-class diagnostic dilemma. Metabolomics 2013, 9, 677-687. [CrossRef] [PubMed]

79. Qin, C.; Yang, G.; Yang, J.; Ren, B.; Wang, H.; Chen, G.; Zhao, F.; You, L.; Wang, W.; Zhao, Y. Metabolism of pancreatic cancer: Paving the way to better anticancer strategies. Mol. Cancer 2020, 19, 1-19. [CrossRef] [PubMed]

80. Bahary, N.; Garrido-Laguna, I.; Wang-Gillam, A.; Nyak-Kapoor, A.; Kennedy, E.; Vahanian, N.N.; Link, C.J. Results of the phase $\mathrm{Ib}$ portion of a phase I/II trial of the indoleamine 2,3-dioxygenase pathway (IDO) inhibitor indoximod plus gemcitabine/nabpaclitaxel for the treatment of metastatic pancreatic cancer. J. Clin. Oncol. 2016, 34, 452. [CrossRef]

81. Kaur, J.; Mir, T.; Gill, R.; Duong, J.; Marcus, S.; Khan, R. Immunotherapeutic approach for advanced pancreatic adenocarcinoma. Immunotherapy 2021, 13, 767-782. [CrossRef]

82. Unlu, A.; Kirca, O.; Ozdogan, M.; Nayır, E. High-dose vitamin C and cancer. J. Oncol. Sci. 2016, 1, 10-12. [CrossRef]

83. Hosein, A.N.; Beg, M.S. Pancreatic Cancer Metabolism: Molecular Mechanisms and Clinical Applications. Curr. Oncol. Rep. 2018, 20, 56. [CrossRef]

84. Grasso, C.; Jansen, G.; Giovannetti, E. Drug resistance in pancreatic cancer: Impact of altered energy metabolism. Crit. Rev. Oncol. 2017, 114, 139-152. [CrossRef] [PubMed]

85. Vermeersch, K.A.; Styczynski, M.P. Applications of metabolomics in cancer research. J. Carcinog. 2013, 12, 9. [CrossRef] [PubMed]

86. Desmetz, C.; Mange, A.; Maudelonde, T.; Solassol, J. Autoantibody signatures: Progress and perspectives for early cancer detection. J. Cell. Mol. Med. 2011, 15, 2013-2024. [CrossRef] [PubMed]

87. Gold, D.V.; Modrak, D.E.; Ying, Z.; Cardillo, T.M.; Sharkey, R.M.; Goldenberg, D.M. New MUC1 Serum Immunoassay Differentiates Pancreatic Cancer From Pancreatitis. J. Clin. Oncol. 2006, 24, 252-258. [CrossRef] [PubMed]

88. Bloomston, M.; Zervos, E.E.; Rosemurgy, A.S. Matrix metalloproteinases and their role in pancreatic cancer: A review of preclinical studies and clinical trials. Ann. Surg. Oncol. 2002, 9, 668-674. [CrossRef] [PubMed]

89. Dangi-Garimella, S.; Krantz, S.B.; Barron, M.R.; Shields, M.A.; Heiferman, M.J.; Grippo, P.J.; Bentrem, D.J.; Munshi, H.G. ThreeDimensional Collagen I Promotes Gemcitabine Resistance in Pancreatic Cancer through MT1-MMP-Mediated Expression of HMGA2. Cancer Res. 2011, 71, 1019-1028. [CrossRef]

90. Bausch, D.; Thomas, S.; Mino-Kenudson, M.; Fernández-Del, C.C.; Bauer, T.W.; Williams, M.; Warshaw, A.L.; Thayer, S.P.; Kelly, K.A. Plectin-1 as a Novel Biomarker for Pancreatic Cancer. Clin. Cancer Res. 2011, 17, 302-309. [CrossRef] [PubMed]

91. Konkalmatt, P.R.; Deng, D.; Thomas, S.; Wu, M.T.; Logsdon, C.D.; French, B.A.; Kelly, K.A. Plectin-1 Targeted AAV Vector for the Molecular Imaging of Pancreatic Cancer. Front. Oncol. 2013, 3, 84. [CrossRef]

92. Xing, L.; Shi, Q.; Zheng, K.; Shen, M.; Ma, J.; Li, F.; Liu, Y.; Lin, L.; Tu, W.; Duan, Y.; et al. Ultrasound-Mediated Microbubble Destruction (UMMD) Facilitates the Delivery of CA19-9 Targeted and Paclitaxel Loaded mPEG-PLGA-PLL Nanoparticles in Pancreatic Cancer. Theranostics 2016, 6, 1573-1587. [CrossRef]

93. Le, U.M.; Hartman, A.; Pillai, G. Enhanced selective cellular uptake and cytotoxicity of epidermal growth factor-conjugated liposomes containing curcumin on EGFR-overexpressed pancreatic cancer cells. J. Drug Target. 2017, 26, 676-683. [CrossRef]

94. Lu, G.-H.; Shang, W.-T.; Deng, H.; Han, Z.-Y.; Hu, M.; Liang, X.-Y.; Fang, C.-H.; Zhu, X.-H.; Fan, Y.-F.; Tian, J. Targeting carbon nanotubes based on IGF-1R for photothermal therapy of orthotopic pancreatic cancer guided by optical imaging. Biomaterials 2019, 195, 13-22. [CrossRef]

95. Camp, E.R.; Wang, C.; Little, E.C.; Watson, P.M.; Pirollo, K.F.; Rait, A.; Cole, D.J.; Chang, E.H.; Watson, D.K. Transferrin receptor targeting nanomedicine delivering wild-type p53 gene sensitizes pancreatic cancer to gemcitabine therapy. Cancer Gene Ther. 2013, 20, 222-228. [CrossRef]

96. Chen, J.; Ke, X.; He, Z.; Gong, H.; Zhang, Y.; Yao, J.; Deng, L.; Yang, D.; Jing, X. A MSLN-targeted multifunctional nanoimmunoliposome for MRI and targeting therapy in pancreatic cancer. Int. J. Nanomed. 2012, 7, 5053-5065. [CrossRef] [PubMed]

97. Medarova, Z.; Pham, W.; Kim, Y.; Dai, G.; Moore, A. In vivo imaging of tumor response to therapy using a dual-modality imaging strategy. Int. J. Cancer 2006, 118, 2796-2802. [CrossRef] [PubMed]

98. Yallapu, M.M.; Ebeling, M.C.; Khan, S.; Sundram, V.; Chauhan, N.; Gupta, B.K.; Puumala, S.E.; Jaggi, M.; Chauhan, S.C. Novel Curcumin-Loaded Magnetic Nanoparticles for Pancreatic Cancer Treatment. Mol. Cancer Ther. 2013, 12, 1471-1480. [CrossRef] [PubMed]

99. Zou, Q.; Zhang, C.; Yan, Y.; Min, Z.; Li, C. MUC-1 aptamer targeted superparamagnetic iron oxide nanoparticles for magnetic resonance imaging of pancreatic cancer in vivo and in vitro experiment. J. Cell. Biochem. 2019, 120, 18650-18658. [CrossRef]

100. Kulkarni, P.S.; Haldar, M.K.; Nahire, R.R.; Katti, P.; Ambre, A.H.; Muhonen, W.W.; Shabb, J.B.; Padi, S.K.R.; Singh, R.; Borowicz, P.P.; et al. MMP-9 Responsive PEG Cleavable Nanovesicles for Efficient Delivery of Chemotherapeutics to Pancreatic Cancer. Mol. Pharm. 2014, 11, 2390-2399. [CrossRef]

101. Wang, X.; Zhang, B.; Xing, X.; Liu, F.; Cheng, Y.; Shi, D. Surface engineered antifouling optomagnetic SPIONs for bimodal targeted imaging of pancreatic cancer cells. Int. J. Nanomed. 2014, 9, 1601-1615. [CrossRef]

102. Chen, X.; Zhou, H.; Li, X.; Duan, N.; Hu, S.; Liu, Y.; Yue, Y.; Song, L.; Zhang, Y.; Li, D.; et al. Plectin-1 Targeted Dual-modality Nanoparticles for Pancreatic Cancer Imaging. EBioMedicine 2018, 30, 129-137. [CrossRef] [PubMed] 
103. Sun, C.; Lee, J.S.; Zhang, M. Magnetic nanoparticles in MR imaging and drug delivery. Adv. Drug Deliv. Rev. 2008, 60, $1252-1265$. [CrossRef]

104. Sun, F.; Zhu, Q.; Li, T.; Saeed, M.; Xu, Z.; Zhong, F.; Song, R.; Huai, M.; Zheng, M.; Xie, C.; et al. Regulating Glucose Metabolism with Prodrug Nanoparticles for Promoting Photoimmunotherapy of Pancreatic Cancer. Adv. Sci. 2021, 8, 2002746. [CrossRef]

105. Zhu, L.; Staley, C.; Kooby, D.; El-Rays, B.; Mao, H.; Yang, L. Current status of biomarker and targeted nanoparticle development: The precision oncology approach for pancreatic cancer therapy. Cancer Lett. 2017, 388, 139-148. [CrossRef]

106. Winter, J.M.; Brennan, M.; Tang, L.H.; D’Angelica, M.I.; DeMatteo, R.P.; Fong, Y.; Klimstra, D.S.; Jarnagin, W.R.; Allen, P.J. Survival after Resection of Pancreatic Adenocarcinoma: Results from a Single Institution over Three Decades. Ann. Surg. Oncol. 2011, 19, 169-175. [CrossRef]

107. Kondo, N.; Murakami, Y.; Uemura, K.; Hayashidani, Y.; Sudo, T.; Hashimoto, Y.; Nakashima, A.; Sakabe, R.; Shigemoto, N.; Kato, Y.; et al. Prognostic Impact of Perioperative Serum CA 19-9 Levels in Patients with Resectable Pancreatic Cancer. Ann. Surg. Oncol. 2010, 17, 2321-2329. [CrossRef] [PubMed]

108. Barton, J.G.; Bois, J.P.; Sarr, M.G.; Wood, C.M.; Qin, R.; Thomsen, K.M.; Kendrick, M.L.; Farnell, M.B. Predictive and prognostic value of CA 19-9 in resected pancreatic adenocarcinoma. J. Gastrointest. Surg. 2009, 13, 2050. [CrossRef]

109. Winter, J.M.; Tang, L.H.; Klimstra, D.S.; Brennan, M.F.; Brody, J.R.; Rocha, F.G.; Jia, X.; Qin, L.; D'Angelica, M.I.; DeMatteo, R.P. A novel survival-based tissue microarray of pancreatic cancer validates MUC1 and mesothelin as biomarkers. PLoS ONE 2012, 7, e40157. [CrossRef]

110. Tobita, K.; Kijima, H.; Dowaki, S.; Kashiwagi, H.; Ohtani, Y.; Oida, Y.; Yamazaki, H.; Nakamura, M.; Ueyama, Y.; Tanaka, M.; et al. Epidermal growth factor receptor expression in human pancreatic cancer: Significance for liver metastasis. Int. J. Mol. Med. 2003, 11, 305-309. [CrossRef]

111. Hirakawa, T.; Yashiro, M.; Murata, A.; Hirata, K.; Kimura, K.; Amano, R.; Yamada, N.; Nakata, B.; Hirakawa, K. IGF-1 receptor and IGF binding protein-3 might predict prognosis of patients with resectable pancreatic cancer. BMC Cancer 2013, 13, 392. [CrossRef] [PubMed]

112. Lin, C.; Wu, W.-C.; Zhao, G.-C.; Wang, D.-S.; Lou, W.-H.; Jin, D.-Y. ITRAQ-based quantitative proteomics reveals apolipoprotein A-I and transferrin as potential serum markers in CA19-9 negative pancreatic ductal adenocarcinoma. Medicine 2016, 95 , e4527. [CrossRef] [PubMed] 